BULLETIN Bulletin hispanique

HISPANIQUE Université Michel de Montaigne Bordeaux

110-1 | 2008

Varia

\title{
Aproximación al Vocabulario de la lengua cakchiquel o guatemalteca (c.1650) de fray Thomás de Coto como fuente léxica del español
}

\section{Esther Hernández}

\section{OpenEdition}

Journals

Édition électronique

URL : https://journals.openedition.org/bulletinhispanique/657

DOI : 10.4000/bulletinhispanique.657

ISSN : 1775-3821

Éditeur

Presses universitaires de Bordeaux

\section{Édition imprimée}

Date de publication : 1 juin 2008

Pagination : 319-331

ISBN : 978-2-86781-511-9

ISSN : 0007-4640

\section{Référence électronique}

Esther Hernández, «Aproximación al Vocabulario de la lengua cakchiquel o guatemalteca (c.1650) de fray Thomás de Coto como fuente léxica del español », Bulletin hispanique [En ligne], 110-1 | 2008, document 11, mis en ligne le 01 juin 2011, consulté le 17 septembre 2021. URL : http:// journals.openedition.org/bulletinhispanique/657 ; DOI : https://doi.org/10.4000/bulletinhispanique. 657 


\title{
Aproximación al Vocabulario de la lengua cakchiquel o guatemalteca (c.1650) de fray Thomás de Coto como fuente léxica del español ${ }^{1}$
}

\author{
ESTHER HERNÁNDEZ \\ Instituto de Lengua, Literatura y Antropología, CSIC - Madrid
}

Les vocabulaires bilingues espagnol - langues amérindiennes de l'époque coloniale constituent des sources précieuses pour l'histoire du lexique espagnol en Amérique. Cet article a pour objet de montrer que le Vocabulario de Coto (c.1650), dont la langue de départ est l'espagnol, enregistre de nombreux néologismes. Il aborde aussi la question de savoir si son auteur a pu sinspirer $d u$ Trésor de la Langue de Covarrubias (1611), et il décrit la méthode lexicographique qui y est mise en œuvre.

Los vocabularios bilingües del español con las lenguas indigenas americanas de la época colonial constituyen fuentes valiosas para conocer la historia del léxico del español en América. En este artículo se pretende mostrar que el Vocabulario de Coto (c.1650), que tiene como lengua de partida la española, documenta neologismos. Se aborda también la cuestión de si su autor pudo inspirarse en el Tesoro de la lengua de Covarrubias (1611), al tiempo que se describe su técnica lexicográfica.

1. Utilizamos un microfilm del manuscrito Vocabulario de la lengua cakchiquel y Guatimalteca, nueuamente hecho y recopilado con summo estudio, trauajo y erudición, depositado en la American Philosophical Society de Filadelfia, signatura 497.43:C82. También seguimos la única edición existente: Fray Thomas de Coto, [Thesavrus Verborvm] Vocabulario..., edición, introducción, notas, apéndices e índices de René Acuña, México, UNAM, 1983. La primera versión de este estudio la presentamos en el VI Congreso Internacional de El Español de América, Tordesillas, 25 al 29 de octubre de 2005.

$B H i$, Tome 110, n $^{\circ} 1$ - juin 2008 - p. 319 à 331. 


\section{BULLETIN HISPANIQUE}

The bilingual vocabularies of Spanish and indigenous languages from the colonial period are valuable sources for learning the history of the Spanish lexicon in America. In this article, we attempt to show that the Vocabulario de Coto (c1650) has the Spanish language as its starting point and contains abundant neologisms. Additionally, we deal with the question of whether or not the vocabulary of Coto was inspired by the Tesoro de la lengua by Covarrubias (1611), while describing its lexicographical methodology.

Mots-clés : Lexicologie - Lexicographie - Diachronie - Espagnol d'Amérique Langues en contact - Langues mayas.

\section{PRELIMINARES}

U NA concepción rigurosa de la historia de la lexicografía española debería incluir los diccionarios, vocabularios o glosarios que tienen como lengua de partida el español ${ }^{2}$. Sin embargo, los vocabularios bilingües que elaboraron los misioneros en América durante la época colonial no suelen ser tenidos en cuenta ${ }^{3}$, aun teniendo muchos de ellos -como el que nos ocupa de fray Thomás de Coto- los lemas en español.

Cierto es que sus autores no se plantearon reunir una lista de entradas del modo en que se hace hoy en los diccionarios léxicos ${ }^{4}$, pero conviene tener en cuenta que, en líneas generales, inventariaron un vocabulario bastante ajustado a la realidad de la lengua española del momento y del lugar, lo que equivale a decir que recogieron un léxico muy matizado ya por la presencia de indigenismos y de americanismos. En este sentido los vocabularios que redactaron los misioneros son fuentes valiosas que no han sido utilizadas

2. Partimos de la idea de P. Álvarez de Miranda, para quien un diccionario español sería uno «en que la lengua de partida, la lengua de los lemas o encabezamientos de artículo, es la lengua espańola» («Hacia una historia de los diccionarios espańoles en la Edad Moderna», Bulletin Hispanique, 97, 1995, p. 189).

3. Cf. Cinco siglos de lexicografia del español. IV Seminario de Lexicografía Hispánica, Jaén, 17 al 19 de noviembre de 1999, edición de I. Ahumada, Jaén, Universidad de Jaén, 2000; G. Haensch, Textos clásicos sobre la historia de la lexicografia del español de América, Madrid, Biblioteca Nacional de España/ Ayuntamiento de Madrid, 2000, 1 CD; M.A. Quesada Pacheco, "Lexicografía del español de América Central: esbozo histórico», Lexicografía y Lexicología en Europa y América. Homenaje a Günther Haensch en su 80 aniversario, Madrid, Gredos, 2003, p. 547-558.

4. Al igual que la lexicografía multilingüe europea surgida en el Renacimiento, la de las lenguas amerindias no está compuesta por vocabularios que recogen sistemáticamente el léxico. No son, por tanto, diccionarios lingüiśticos según los concibe L.F. Lara: «El diccionario y sus disciplinas», Revista Internacional de Lingüistica Iberoamericana, I, 1, 2003, p. 42. 
y debemos aprovechar, pues encierran un tesoro léxico con interesantes materiales para el conocimiento de la historia del español americano.

Estos vocabularios se han visto como repertorios que siguen excesivamente de cerca la nomenclatura del Vocabulario español-latino de Nebrija ${ }^{5}$, debido, en gran medida, a la opinión que Samuel Gili Gaya expresó sobre los mismos en el Prólogo de su obra o Tesoro lexicográfico:

Tampoco figuran en ella los numerosos vocabularios españoles en lenguas indígenas americanas, que los misioneros compusieron. Los que hemos podido examinar contienen escaso léxico espańol y nada añaden a los diccionarios europeos, especialmente a Nebrija, que los misioneros tomaban como guía para componer los suyos, escogiendo las palabras de significado asequible a la mentalidad indígena ${ }^{6}$.

Antes bien, muchos de los autores no se limitaron a sustituir el latín por la lengua indígena, sino que incorporaron novedades léxicas y abundantes neologismos americanos en el texto castellano de sus vocabularios bilingües, según hemos mostrado en otras ocasiones ${ }^{7}$.

Como veremos, el Vocabulario de fray Thomás de Coto sobre la lengua de Guatemala, compuesto a mediados del siglo XVII, es una obra original dentro de la lexicografía hispanoamericana por muchas razones, especialmente por lo que respecta a su técnica. Es interesante, además, porque las entradas (y las

5. Elio Antonio de Nebrija, Vocabulario español-latino, facsímil de la primera edición (ca.1495), patrocinado por la Asociación de Amigos de la Real Academia Española, Madrid, RAE, 1989.

6. S. Gili Gaya, Tesoro lexicográfico (1492-1726), (A-CH), Madrid, CSIC, 1947, p. viii. Argumento rebatido con diversas razones por I. Acero Durántez, «Una aportación a la historia de la lexicografía americana. Sobre El Vocabulario en lengua de Michoacán de fray Maturino Gilberti», Estudios de lexicografía diacrónica del español (V Centenario del Vocabularium Ecclesiasticum de Rodrigo Fernández de Santaella), coord. A. M. Medina Guerra, Málaga, Universidad de Málaga, 2001, p. 96; R. Acuńa, op. cit., p. xxx; E. Hernández, «Contribución a la historia de la lexicografía en América: los vocabularios bilingües del siglo XVI», VI Congreso Internacional de Historia de la Lengua española, Madrid, 29 de septiembre - 3 de octubre de 2003, inédito, y T. C. Smith Stark., «La aportación de los diccionarios bilingües de la Nueva España a la lexicografía del español», III Coloquio de Historiografía de la Lingüistica Hispánica, El Colegio de México-México, 25 de septiembre de 2002, inédito.

7. Véase E. Hernández, «El Vocabulario náhuatl de Molina frente al Vocabulario de Nebrija», Iberorromania, 52, pág. 4; id., "Influencias de método y concepción entre los vocabularios novohispanos del siglo XVI», América y el diccionario, eds. M. Campos Souto, F. Córdoba y J. I. Pérez Pascual, A Coruña, Universidade da Coruña, 2006, p. 63-77 [Anexos de Revista de Lexicografia, 2]. 
subentradas) suelen aparecer autodefinidas del mismo modo que sucede en los diccionarios bilingües del español clásico, empezando por el Vocabulario de Nebrija. En tales definiciones o explicaciones, que dan lugar a sintagmas o unidades pluriverbales en la propia entrada, hay un material histórico útil no solo en el nivel léxico, sino también en los niveles fonográfico (por estar manuscrito), morfológico y sintáctico.

\section{FRAY THOMÁS DE COTO}

El franciscano fray Thomás de Coto parece ser que había nacido en Guatemala en los primeros ańos del siglo XVII ${ }^{8}$. Él mismo aseguraba en el texto castellano de su repertorio que el español era su lengua. En realidad, las fuentes con noticias de su vida empiezan por su obra, dado que forma parte de su estilo -característico, por otro lado, de la época del Barroco- el hacer referencias a sí mismo. También las hay en la crónica de fray Francisco Vázquez (nacido en 1647), quien afirmaba que Coto era "criollo» ${ }^{9}$. Finalmente, existen varias cartas autógrafas dirigidas al Consejo de Indias de cuando estuvo en España, esto es, del año 1643 al $1646^{10}$.

Fue durante esta estancia en España, para R. Acuña, cuando «tuvo conocimiento del Tesoro de la lengua de Covarrubias, y cuando probablemente concibió la idea del suyo" (op. cit. p. xvii). Ésta es una de las razones por las que Acuña editó el vocabulario con el título reconstruido de Thesaurus Verborum. Más adelante tratamos esta reconstrucción, al tiempo que describimos la técnica lexicográfica utilizada por Coto.

\section{LA PRODUCCIÓN LEXICOGRÁFICA EN EL ÁREA}

\section{DE LAS LENGUAS MAYAS Y EL VOCABULARIO DE COTO}

La lexicografía bilingüe del español con las lenguas amerindias apareció a mediados del siglo XVI, antes de que lo hiciera la del español con otras lenguas europeas ${ }^{11}$. Los primeros vocabularios redactados en el área maya

8. Véase R. Acuña, op. cit., p. xiv.

9. Fray Francisco Vázquez, Crónica de la Provincia del Santísimo Nombre de Jesús de Guatemala, prólogo, notas e índices de fray Lázaro Lamadrid, Guatemala, Tip. Nacional, 1937-1944, t. III, cap. 11, p. 262.

10. En los documentos de AGI, Guatemala 178 y 181 (apud, R. Acuña, op. cit., p. xv).

11. Nos referimos, por ejemplo, a las primeras obras del español y el inglés de Richard Percival, Bibliothecae Hispanicae pars altera. Containing a Dictionary in Spanish, English and Latine, Londres, John Jackson y Richard Watkins, 1591, o del español y el francés de Juan 
corresponden también a esa época, pero no tuvieron la suerte de otros idiomas mesoamericanos -como el náhuatl, tarasco, otomí, zapoteco o mixteco- ${ }^{12}$, pues no se llegaron a imprimir, aunque se conserven diversas copias manuscritas distribuidas por distintas instituciones ${ }^{13}$.

El vocabulario de la lengua de Guatemala de fray Thomás de Coto ha llegado en versión manuscrita y es bilingüe de una sola dirección: españolcachiquel. Consta de 477 folios y está incompleto, dado que solo llega a la entrada vendible. Carece de las páginas preliminares, donde suele aparecer expresado el propósito de este tipo de obras, lo que se hacía normalmente con objeto de obtener las licencias oportunas para la impresión. En el cuerpo del texto del diccionario es patente, de todas formas, su finalidad codificadora, esto es, el vocabulario está destinado a servir de ayuda a los frailes en la producción de textos orales o escritos en la lengua cachiquel, una de las lenguas mayas de Guatemala. El cachiquel lo hablan hoy alrededor de 400.000 personas en el centro de Guatemala y está directamente relacionado con el zutujil, que algunos consideran dialecto suyo.

Palet, Diccionario muy copioso de la lengua española y francesa [...] Dictionaire tres ample de la langue espagnole et française, Paris, Matthieu Guillemot, 1604.

12. Fray Alonso de Molina, Aqui comiença vn vocabulario en la lengua castellana y mexicana (1555), ed. de M. Galeote, Univ. de Málaga, 2001; id., Vocabulario en lengua castellana y mexicana (1571), edición facsímil y estudio de E. Hernández, Madrid, Agencia Española de Cooperación Internacional / Biblioteca Nacional, 2001; Maturino Gilberti, Diccionario de la lengua tarasca o de Michoacán (1559), ed. de Antonio Peñafiel, México, Tipografía de la Oficina Imp. de Estampillas, 1901; fray Juan Bautista de Lagunas, Arte y diccionario tarascos (1574), ed. de Nicolás León, Morelia, Imp. y Lit. en la Escuela de Artes, 1890; fray Alonso de Urbano, Arte breve de la lengua otomi y vocabulario trilingüe español-nábuatl-otomí (ca. 1571), ed. de R. Acuña, México, UNAM, 1990; fray Francisco de Alvarado, Vocabulario en lengua mixteca (1593), reproducción facsimilar con un estudio de W. Jiménez Moreno y un apéndice con un Vocabulario sacado del Arte en lengua mixteca de fray Antonio de los Reyes, México, Instituto Nacional Indigenista e Instituto Nacional de Antropología e Historia, 1962.

13. Véase E. Hernández, "Los vocabularios hispano-mayas del siglo XVI», Missionary Linguistics / Lingüistica Misionera. Selected Papers of Vth International Conference on Missionary Linguistics, Mérida-Yucatán, 8-11 de marzo 2007, eds. O. Zwartjes y R. Arzápalo, John Benjamins, Amsterdam / Philadelphia, en prensa. Para una aproximación historiográfica, véase: D. Bolles, The Mayan Franciscan Vocabularies: A Preliminary Survey, 2003 [http:// www.famsi.org]; A. Hernández de León-Portilla, «Las primeras gramáticas mesoamericanas. Algunos rasgos lingüísticos», Historiographia Linguistica, XXX, 1-2, 2003, p. 1-44; H.-J. Niederehe, «Los misioneros españoles y el estudio de las lenguas mayas», Missionary Linguistics / Lingüistica Misionera. Selected Papers from the First International Conference on Missionay Linguistics, Oslo, 13-16 March 2003, eds. O. Zwartjes, E. Hovdhaugen, John Benjamins, Amsterdam/ Philadelphia, 2004, p. 81-91. 
No es ocioso señalar que el vocabulario iba dirigido a los espańoles o a los criollos. De esta manera, si su objetivo era servir como instrumento de trabajo a los frailes españoles en su misión evangelizadora, necesariamente estaba concebido desde la lengua castellana y no a la inversa. Es decir, el léxico castellano que contiene no fue escogido para ser asequible a «la mentalidad indígena», como señaló Gili Gaya (vid. supra), sino que iba dirigido a ampliar la competencia lingüística de los propios frailes ${ }^{14}$, eso sí, ante la nueva situación geográfica y social americana.

El diccionario de Coto parte de una lista de entradas castellanas basada en otros repertorios también con entradas en castellano, los cuales se basan en el Vocabulario de Nebrija. La lengua de partida es, por consiguiente, la castellana, en tanto que las equivalencias en cachiquel se ofrecen siguiendo tal lista de entradas castellanas, ordenada alfabéticamente. Y ello hasta el punto de que, en ocasiones, la lista de las voces españolas no la determina la existencia de una correspondencia cachiquel, como se pone de manifiesto en los siguientes artículos:

alabastro. no le [sic] tienen. Por ser blanco y resplandeçiente, le darán el nombre que al cristal.

a desora. no tienen con propiedad vocablo. Vsan de [...] que es de repente, sin sentir.

alunado. no es entre estos yndios mui conosçida esta enfermedad, ni tienen propio vocablo para ella.

Fray Thomás de Coto expresó su propósito en el texto de diccionario con cierta frecuencia. Así, ya en el título figura lo siguiente: «en que se contienen todos los modos y frases elegantes conque los naturales la hablan, yd[e] q[ue] se pueden valer los ministros estudiosos para su mejor educación y enseñanza». Incluso, por ejemplo, en el artículo correspondiente al encabezamiento de entrada castellana "apetesçer algo», aprovechó para afirmar lo siguiente: «de buena gana he escrito este libro con el que aprenderán algunos padres que no conocen la lengua cachiquel».

Frases como la anterior y otras en tono más coloquial surgen a cada paso en la obra de Coto. En efecto, el diccionario posee un lenguaje muy directo, con alusiones en segunda persona dirigidas a los misioneros que en ocasiones adquieren un matiz paternalista. Así sucede en la entrada «abrir las piernas», a propósito de la cual escribía: «y no tomes esto en mala parte, que todo es necessario saberlo para sauer con perfección el idioma, que tal vez se te ofreçerá estar vna muger de parto y, para echar el agua a la criatura,

14. Opinión de R. Acuña (op. cit. p. xxv), que compartimos. 
necesitarás dezirlo». O en la entrada siguiente, bajo la voz «asar»: «[...] asar en hoyo cubriendo con tierra lo que así se asa, o como asan las pencas de cabuya o maguei o la danta [...] para reprehender a estos naturales y darles a entender las penas del purgatorio es bueno este verbo». Por otro lado, en este artículo se observa la presencia en el español de la zona de los préstamos tomados de las lenguas indígenas (cabuya, de origen caribe, y maguei, de origen antillano) y también se documenta el americanismo danta, palabra del fondo léxico patrimonial que sufrió un cambio semántico en América utilizándose para designar el animal hoy más conocido en español mediante el indigenismo tapir (de origen tupí).

\section{TÉCNICA LEXICOGRÁFICA}

El estilo personalizado del vocabulario de Coto se aparta de la tradición lexicográfica que dominaba en América. Los vocabularios mesoamericanos compuestos por los misioneros que le precedieron, los de Molina, Gilberti, Urbano, Córdova, Alvarado, etc., todos ellos procuraban borrar cualquier huella personal y no permitían deslizar lo anecdótico, lo que les confirió una expresión más cercana a la obra de Nebrija. En cambio, la visión de las cosas eminentemente práctica de fray Thomás de Coto puede percibirse de modo constante en el texto, lo que, por otra parte, convierte al diccionario en una fuente de noticias no solo de tipo lingüístico, sino también de tipo histórico y antropológico. Así, en la entrada encabezada por la voz «acaso» decía el autor: «antes de llegar a poner este exemplo, a las dos de la tarde, sábado 18 de febrero, fue el gran terremoto de Guat[emal]a. Y me coxió escriuiendo esto, que, desde dicho exemplo, le prosigo oy, sábado 25 de marzo de 1651, en este convento de Almolonga».

El tono subjetivo ciertamente podría recordar al estilo del primer diccionario monolingüe del español, el Tesoro de la lengua de Sebastián de Covarrubias ${ }^{15}$. Como ya hemos señalado más arriba, R. Acuña editó el manuscrito con el título reconstruido de Thesaurus verborum con la intención de acercarlo, nominalmente mediante título semejante, a la obra de Covarrubias ${ }^{16}$. Sin embargo, cabe objetar que la denominación tesoro,

15. Sebastián de Covarrubias, Tesoro de la lengua castellana o española, Madrid, Luis Sánchez, 1611 (Ejemplar del CSIC, IFL Signatura: CVI-G/78). Unos magníficos estudios sobre este diccionario pueden consultarse en M. Seco, Estudios de lexicografía española, Madrid, Gredos, 2003, 2a ed. aumentada, p. 185-236.

16. R. Acuńa afirma que se inspiró en Covarrubias, pero no ofrece argumentos para refutarlo, tan solo que una fuente antigua se refiere a su diccionario con este título (op. cit. 
en palabras de Manuel Seco, «había sido usada, en efecto, por la lexicografía europea, especialmente francesa, para designar diccionarios bilingües o plurilingües cuya riqueza se ponderaba ${ }^{17}$. Por lo tanto, de haber puesto Coto el título de Thesaurus verborum a su obra se situaría en tal tradición $y$, en consecuencia, no seguiría necesariamente a Covarrubias, quien sí fue original en utilizar esta denominación de tesoro, pero para un diccionario monolingüe.

Otro de los rasgos del método seguido por Coto que podría recordar al utilizado por Covarrubias es el del uso de autoridades. Como es sabido, Covarrubias se adelanta en este aspecto a los diccionarios académicos del italiano, del francés y del español. Por su parte, Coto utilizó textos de los autores religiosos que le precedieron para documentar los usos lingüísticos de la lengua cachiquel, en ningún caso para ilustrar el uso del castellano. Escribe, por ejemplo: $\mathrm{Nu}$ [est]ro P [adr]e Saz, Serm[one] de Samaritana, diçe, por el poço, quotom ya y por el bocal, q,akam ibahim ru chi, id est, "q[ue] tiene çimiento o obra a la boca», s.v. «bocal o brocal de poço».

Tal uso de autoridades es novedoso en la lexicografía americana. Coto no necesitaba inspirarse en Covarrubias, sino que tal vez lo que subyace en su vocabulario es la imitación del famoso diccionario de Ambrosio Calepino ${ }^{18}$, en el cual, dicho sea de paso, también se inspiró Covarrubias.

La obra de Calepino era conocida por los franciscanos en América, de quien fray Bernardino de Sahagún señalaba: "porque Calepino sacó los vocablos y las significaciones de ellos, y sus equivocaciones y metáforas de los poetas y oradores y de otros autores de la lengua latina, autorizando todo lo que dice con los dichos de los autores, tal fundamento me ha faltado a mí» ${ }^{19}$. Sin embargo, fray Thomás de Coto, a mediados del siglo XVII, casi un siglo después de que Sahagún escribiera lo anterior, ya disponía de trabajos previos sobre el cachiquel. De ahí procede el título «nuevamente

p. xliv). Llama nuestra atención el hecho de que Coto no mencionara a Covarrubias si conocía su obra; otros lexicógrafos de la época también lo utilizaron, como Oudin, Franciosini e incluso Ménage (v. M. Seco, op. cit. p. 223).

17. Según M. Seco, «Covarrubias no fue el primero que lo usó, hay cuatro thesaurus españoles inscritos en la tradición europea de los bilingües y plurilingües, el de Sumarán (1626), el de Salas (1645), el de Henríquez (1679) y el de Requejo (1717) además del primero de ellos, el de Bartolomé Bravo, de 1597» (ibidem).

18. Dictionarium: Quanta maxima fide ac diligentia fieri potuit accuratè emendatum multisque partibus cumulatum. Adiectae sunt latinis dictionibus hebraeae, graecae, italicae, germanicae et hispanicae, Ambrosius Calepini, Lion, 1581 [1502] (apud ejemplar del CSIC, IFL Signatura: CVI-CF-4).

19. Fray Bernardino de Sahagún, Historia general de las cosas de Nueva España, México, Porrúa, 1956, I, p. 32 (apud Acuña, op. cit.). 
hecho y recopilado, con mucho trabajo y erudición». Las autoridades que cita son fray Domingo de Vico, fray Pedro de Betanzos, fray Juan Alonso, fray Francisco de Varea, fray Francisco Maldonado y fray Antonio del Saz.

R. Acuña define un calepino como un diccionario de autoridades (op cit. xxvi), pero hay que advertir que esta palabra tenía otro significado de acuerdo con las documentaciones existentes de esta palabra ${ }^{20}$. Así, el cronista de la misión franciscana fray Gerónimo de Mendieta escribió que Sahagún "compuso un Calepino (que así lo llamaba él) de doce o trece cuerpos de marca mayor, los cuales yo tuve en mi poder» ${ }^{21}$. Y es que el uso de la palabra calepino, neologismo acaso introducido en América por Sahagún, según se desprende de esta cita de Mendieta, merecería un estudio histórico aparte. Concretamente, lexicógrafos americanos, como Lagunas, utilizaron también el término calepino como sinónimo de diccionario bilingüe, pero no como diccionario de autoridades ${ }^{22}$.

Con todo, el diccionario de Coto es original en el sentido de que está basado en un concepto moderno de diccionario bilingüe por utilizar los dos procedimientos, el de la autoridad por un lado, y el de dar ejemplos en las definiciones por otro. En efecto, cada entrada o subentrada dentro de un artículo va enriquecida con frases como ejemplos de uso. Así, en el artículo para la entrada «bentura» aparecen las siguientes frases dentro de la subentrada "prueba de bentura»: xa nu tibbal nu 3ih qui r'ah be canan. quiero ver o prouar q[ué] bentura tengo. nak $x$-ta tihbeh a 3ih?. ¿con q[ué] as de prouar tu bentura?. yn qui be tihol nu 3ih, ti be nu tiha nu qay cohol hay. voy a ver si puedo vender algo. A partir de la palabra clave de la entrada, recoge sintagmas o frases castellanas relacionadas, a las que asigna su correspondiente equivalencia en cachiquel.

20. Cf. documentaciones de la voz calepino en Corpus diacrónico del español o CORDE (http://www.rae.es/) y en el Corpus del español de M. Davies (http://www.corpusdelespanol. org/), o en la base de datos de P. Boyd-Bowman, Léxico Hispaoamericano (1493-1993), eds. R. Harris-Northall y J. Nitti, CD-Rom, Hispanic Seminary of Medieval Studies, 2003.

21. Fray Gerónimo de Mendieta, Historia eclesiástica indiana. Obra escrita a fines del siglo XVI, ed. de J. García Icazbalceta, México, Antigua Librería, 1870 (ca. 1596], libro IV, capítulo 44. Véase P. Máynez, El Calepino de Sahagún: un acercamiento, prólogo de M. León-Portilla, México, Universidad Nacional Autónoma de México / Fondo de Cultura Económica, 2002.

22. Las palabras iniciales de su vocabulario, que carece de autoridades, como otros coetáneos, son las siguientes: «Aquí comiença lo más substancial del Vocabulario de Michoacán hecho y recopilado por Fray Iuan Baptista de Lagunas, de la orden del Seráphico padre sant Francisco, y podrase llamar Dictionarito, porque el autor (para más provecho de los estudiantes) sigue en el orden y modo del Ambrosio Calepino [...] (México, 1547)». 
A todo ello es necesario añadir que hay un rasgo que singulariza la microestructura del diccionario, que lo separa de la tradición nebrisense y, en consecuencia, de la primera lexicografía americana : las acepciones y los derivados se hallan dentro de cada artículo, si bien de manera muy irregular o asistemática, como veremos en el siguiente apartado.

\section{MICROESTRUCTURA DEL VOCABULARIO}

Como es sabido, los diccionarios bilingües americanos de la época colonial, y los españoles de la época clásica en general, no fueron compuestos ni redactados como los diccionarios actuales, según los principios de estructuración sistemática de la información distribuida por campos. Ello equivale a decir que son diccionarios sin base científica sólida en el aspecto lingüístico. En el vocabulario de Coto se observa irregularidad en el orden de la microestructura, pues dentro de cada artículo podemos encontrar, de manera variable, los siguientes campos de información:

I) La entrada, definida con sinónimos o acompañada de (en ocasiones, prolijas) explicaciones, por ejemplo : «bejucos, que son como parras y trepan por los árboles y les siru[en] de cordeles o mecates para edificar sus casas y otros trabajos»; «bodoquear o cerbatanear»; «borra o asiento de alguna cosa líquida o las hezes»; «bordón, palo sobre q[ue] se sustenta el viejo o enfermo".

2) La equivalencia cachiquel.

3) Las marcas, siempre referidas al cachiquel: a) de categorías gramaticales, muy abundantes, que lo apartan aún más de la modernidad inaugurada por la obra lexicográfica de Nebrija, por ejemplo: «esta partícula naek sirve para formar tiempos de pretérito imperfecto, de presente de indicativo"; b) de pronunciación, por ejemplo: «y así este verbo, como todos los demás $\mathrm{q}[\mathrm{ue}]$ empieçan en $\mathrm{x}[. .$.$] se varían con las partículas y pronombres de los$ q[ue] empiezan en vocal, porq[ue] en la pronunçiación y escriptura se les antepone esta letra, i»; c) de uso, por ejemplo: «estoi affligido, soi pobre, fáltame mi comida y bebida, luego lloro. Deste lenguaje vsan los viejos y viejas y viudas, y suelen moler ['molestar gravemente'] con esto quando se confiesan. $Y$ alguno dirá que también muelo yo en ponerlo aquí, y quizá ni sauía ni auía entendido quando se lo ayan dicho».

4) Las autoridades, con los nombres de los autores y los títulos de las obras que emplean las voces mayas concernidas.

5) Los ejemplos, con frases en cachiquel ilustrativas de la voz de la entrada, seguidas de una traducción adecuada a la estructura semántica del castellano. Ésta, a su vez, puede ir seguida de otra muy literal e inapropiada 
en castellano. Por ejemplo : "por estar alegrísimo y contento, diçen [...]", «está como remojado mi coraçón en miel, en alegría».

6) La familia léxica o las acepciones, que aparecen dentro del cuerpo del artículo a modo de subentradas, donde podemos encontrar, a su vez, todos los elementos anteriores. Por ejemplo, dentro del artículo de «bebida para esforçar» aparecen las siguienes subentradas, donde abundan los indigenismos léxicos: «bebida de cacao molido con maíz, pinole»; «bebida de cacao con mucho chile»; «bebida de cacao con xúchiles»; «bebida de chian y maiz tostado"; «bebida de maíz nuebo, crudo». También como subentradas hallamos derivados. Así, en la entrada «bellaco ser en hablar», aparecen: «bellaquería o maldad así»; «abellacar a otro, haciéndolo bellaco»; «el bellaco incorregible»; «bellaquería así; embellacar a otro», etc. En este caso, el desorden es manifiesto, pues no es raro que Coto cambie la dirección, colocando en primer término la palabra cachiquel seguida del equivalente castellano.

7) Los reenvíos intratextuales o remisiones internas, por ejemplo: «abrasar con fuego. vide quemar; abrasarse de calor. vide calor».

Por tanto, el método de Thomás de Coto para la composición de su diccionario puede resumirse en los siguientes aspectos: primero, se apoyaría en la tradición renacentista, distinta de Nebrija, tal vez inspirado en el diccionario de Calepino en el uso de autoridades; segundo, no posee el rigor metodológico de Nebrija, pese a que es evidente que utiliza su nomenclatura, así como la del vocabulario de fray Alonso de Molina, como explicaremos a continuación; y tercero, la estructura de los artículos nada tiene que ver con la del Tesoro de Covarrubias, aunque comparte con éste su estilo barroco, de tono personal y acumulativo en cuanto a la información de todo tipo que proporciona $^{23}$.

Lo más seguro es que en la elaboración de la nomenclatura Coto se apoyara en el Vocabulario del cachiquel de fray Juan Alonso, quien a su vez copió literalmente las entradas castellanas de la edición de Molina de 1571, según hemos mostrado en otra ocasión ${ }^{24}$. Esto puede observarse desde la primera entrada de Coto, idéntica a la de Molina y, en consecuencia, a la del vocabulario cachiquel de Alonso: aa «interjección intelectiva del que haya a otro haziendo un maleficio». Además, hemos comprobado que

23. Un estudio contrastivo del léxico de las entradas de ambos, imprescindible antes de dar una opinión concluyente sobre si se basó o no en Covarrubias, se halla en curso de preparación por nuestra parte.

24. Se refiere a Juan Alonso como el autor del vocabulario antiguo y lo cita de modo continuado. Véase nuestro estudio sobre los vocabularios mayas, cit. n. 13. 
los utilizó cotejando las entradas que comienzan por la letra b- de los dos vocabularios ${ }^{25}$. No obstante, aunque basado o inspirado en la obra de estos lexicógrafos, el vocabulario de la lengua de Guatemala es original en la elaboración del inventario de las entradas, que lo singularizan como una obra de interés para la lexicología histórica hispánica.

\section{NOVEDADES LÉXICAS}

Como sucede siempre en lexicografía, Coto se basó en diccionarios previos en la confección de las entradas, pero también se paró a reflexionar y a decidir qué nuevos vocablos introducir, e incluso los definió en la propia entrada ${ }^{26}$. Por ello, el repertorio de Coto tiene especial valor para la historia del léxico de Guatemala por las palabras que utiliza o que registra, muchas de las cuales son neologismos interesantes para el conocimiento del español en América y, en particular, del léxico de esa región centroamericana.

Con mucha frecuencia hallamos palabras procedentes de las lenguas indígenas, como milpa, xicara, guaipil, chinamital, chocolate, coyote, etc., así como americanismos como garúa ${ }^{27}$, tortilla, tigre, etc.

Además, desde el punto de vista lexicográfico es importante saber que Coto lematizó indigenismos como amole, atole, axin, çigarro, etc., los cuales aparecen registrados antes que en los diccionarios que recogen los corpus del $N T L L E^{28}$ y el $N T L E^{29}$, así como en el Tesoro lexicográfico de Gili Gaya. Asimismo hay palabras del fondo léxico patrimonial, como abohetado, actualidad, asperjar, atenacear, que aparecen registradas por primera vez, $\mathrm{y}$ que permiten adelantar su fecha de registro lexicográfico.

25. Resulta evidente que Coto cotejó los vocabularios de Alonso o de Molina tras comprobar que las entradas que Molina introdujo como novedades respecto al nebrisense, en sus ediciones de c. 1495 y 1516, se encuentran en el de Coto de modo literal (cf. balsa, bannas, bezerro, etc.).

26. Las palabras del fondo patrimonial no dejan de constituir novedades en un diccionario con entradas en español relativamente temprano y, lo que resulta más interesante ahora, del español americano.

27. Occidentalismo léxico transmitido desde la Andalucía occidental (Véase J. Ma Enguita Utrilla, Para la historia de los americanismos léxicos, Frankfurt am Main, Peter Lang, 2004, p. 21).

28. Real Academia Española, Nuevo Tesoro Lexicográfico de la Lengua Española, Madrid, Espasa Calpe, Edición en DVD, 2001.

29. L. Nieto Jiménez y M. Alvar Ezquerra, Nuevo Tesoro Lexicográfico del español (s. XIV1726), Madrid, Real Academia Espańola / Arco Libros, 2007. 
En definitiva, este vocabulario, como muchos otros redactados en la época colonial en América, cayó en el vacío en su tiempo y es un perfecto desconocido para la filología espańola en la actualidad. Sin embargo, como acabamos de exponer, es una fuente valiosa para el estudio del léxico histórico del español de América, amén de constituir un inestimable archivo de datos sobre el contacto entre la lengua y la cultura espańolas y la lengua y la cultura mayas. 